\title{
interferansiyel Akımların Kronik Miyofasyal Ağrı Sendromunda Kısa Dönem Etkinliği
}

\section{Short-Term Effects of Interferential Currents on Chronic Myofascial Pain Syndrome}

\author{
Demet OFLUOĞLU, Elif AYDIN BULAK*, Nilüfer KABLAN**, Gülseren AKYÜZ*** \\ Başkent Üniversitesi Tıp Fakültesi, Fiziksel Tıp ve Rehabilitasyon Anabilim Dalı, Istanbul, Türkiye \\ *Adnan Menderes Üniversitesi Tıp Fakültesi, Fiziksel Tıp ve Rehabilitasyon Anabilim Dalı, Aydın, Türkiye \\ **Marmara Üniversitesi Sağlık Bilimleri Fakültesi Fizyoterapi ve Rebahilitasyon Bölümü, Istanbul, Türkiye \\ * *Marmara Üniversitesi Tıp Fakültesi, Fiziksel Tıp ve Rehabilitasyon Anabilim Dalı, Istanbul, Türkiye
}

\section{Özet}

Amaç: Miyofasyal ağrı sendomu (MAS) kronik kas ağrısı sebebi olan, tetik noktaların varlığı ile karakterize lokal veya bölgesel ağrı sendromudur. Standart tedavisi oral ilaçlar, enjeksiyonlar, fizik tedavi modaliteleri ve egzersizi kapsar. Bu araştırmanın amacı bir fizik tedavi modalitesi olan interferansiyel akımın kronik MAS'ta kısa dönem etkinliğinin araştırılmasıdır.

Gereç ve Yöntem: Prospektif, randomize-kontrollü bir çalışmadır. Çalışmaya kronik MAS'a bağlı sırt ağrısı olan toplam 40 hasta alındı. Hastalar iki gruba ayrıldı. Birinci gruba vakum + interferansiyel akım (VIFA), ikinci gruba ise sadece vakum tedavisi (VT) uygulandı. Aynı zamanda her 2 gruba eklem hareket açıklığı ve germe egzersizleri ev programı şeklinde gösterildi. Ağrı değerlendirmesi tedavinin başında ve 15. günde Vizüel Analog Skala (VAS) ve algometre ile, hastalık aktivitesi hastanın kendini global değerlendirmesi ve hekimin hastayı global değerlendirmesi yöntemi kullanılarak yapıldı. Hastaların duygu durum değerlendirmesi de Beck Depresyon Ölçeği (BDÖ) ile yapıldı.

Bulgular: Çalışmaya alınan hastaların yaş ortalamaları ViFA grubunda $38,2 \pm 13,2$ yıl ve VT grubunda $48,2 \pm 14,4$ yıl idi. Her iki grubun çalışma başlangıcı ve sonrası değerlendirmelerinde VAS skorlarında, hasta ve hekimin global değerlendirmesinde belirgin iyileşme saptandı $(p<0,05)$. ViFA grubunda aynı zamanda, algometrik ölçümlerde belirgin iyileşme gözlenirken $(p<0,05)$, VT grubunda bu düzelme gözlenmedi $(p>0,05)$. Her iki grupta da BDÖ skorları normal sınırlar içerisinde olup, tedavi sonrasındaki değerlerde anlamlı azalma saptandı $(p<0,05)$.

Sonuç: Interferansiyel akımlar kronik MAS tedavisinde etkin bir tedavi olup, egzersiz gibi diğer tedavi metodları ile kombinasyonu ek yararlar sağlayabilir. Türk Fiz Tıp Rehab Derg 2013,59:209-13.

Anahtar Kelimeler: Analjezik akımlar, elektroterapi, interferansiyel akım, miyofasyal ağrı

\section{Summary}

Objective: Myofascial pain syndrome (MPS) is a local or regional pain syndrome that causes chronic muscle pain characterized by the presence of trigger points. Standard treatment includes oral medicines, injections, physical therapy modalities and exercises. The aim of this study was to investigate the short-term effects of interferential current, which is a physical treatment modality, on chronic myofascial pain syndrome.

Materials and Methods: In this prospective, randomized-controlled study, we included 40 patients with back pain due to chronic myofascial pain syndrome. The patients were divided into two groups. The first group was treated with vacuum and interferential current (VIC) while the second group was given only vacuum treatment (VT). At the same time, range of motion and stretching exercises were suggested as home training. Pain assessment was done at the beginning and on the $15^{\text {th }}$ day of treatment by using a visual analogue scale (VAS) and the disease activity was measured by patients' and physicians' global assessment scale. Mood assessment was performed using the Beck Depression Inventory.

Results: The mean age in the VIC and VT groups was 38.2 \pm 13.2 and $48.2 \pm 14.4$ years, respectively. There was a statistical difference between before and after treatment VAS scores, and patients' and physicians' global assessment in both groups $(\mathrm{p}<0.05)$. Although algometric measurements were statistically significantly improved at the end of the study in group I $(p<0.05)$, those improvements were not observed in group II $(p>0.05)$. The Beck Depression Inventory scores were within normal range in both groups before treatment, however, a significant decrease was found after treatment $(p<0.05)$.

Conclusion: Interferential current therapy is an effective treatment method in chronic MPS. When combined with other treatment methods such as exercise, additional benefits may be obtained. Turk / Phys Med Rehab 2013;59:209-13.

Key Words: Analgesic currents, electrotherapy, interferential currents, myofascial pain

Yazışma Adresi/ Address for Correspondence: Dr. Demet Ofluoğlu, Başkent Üniversitesi Tıp Fakültesi, Fiziksel Tıp ve Rehabilitasyon Anabilim Dalı, İstanbul, Türkiye Tel.: +90 2165541500 E-posta: dofluoglu@hotmail.com

Geliş Tarihi/Received: Ekim/ November 2011 Kabul Tarihi/Accepted: Eylül/September 2012 


\section{Giriş}

Günümüz dünyasında gelişen teknolojik olanaklara paralel olarak artan sedanter yaşam tarzı kas iskelet ağrılarında artışı da beraberinde getirmiştir. Amerika verileri, tüm iş kaynaklı hastalıkların yarıdan fazlasını kümülatif travma kaynaklı kas iskelet sistemi hastalıklarının oluşturduğunu belirtmektedir (1). Sık karşılaştığımız kas iskelet sistemi hastalıklarının başında miyofasyal ağrı sendromu (MAS) gelmektedir. MAS gergin kas bantları içerisinde yerleşmiş tetik noktalar ile karakterize bir kas-iskelet sistemi hastalığıdır. Prevalansı her geçen gün artış göstermekte olup, günümüzde ağrı polikliniklerinde görülme sıklığı \%30-85 olarak bildirilmektedir (2). MAS kronik kas veya kas gruplarında tetik noktaların varlığı ile lokal veya bölgesel ağıı yapan bir hastalıktır. Tetik noktalara bağlı gelişen ağrı, özellikle kronikleşir ise kişilerin günlük yaşam aktivitelerinin etkilenmesine, iş verimliliğinin düşmesine veya depresyona yol açabilir (3).

Ağrılı tetik noktaların tedavisinde pek çok yöntem kullanılmaktadır. Bu noktalara lokal anestezik, serum fizyolojik, botulinum toksin, steroid enjeksiyonları ile kuru iğneleme teknikleri gibi invaziv müdahaleler yapılabilmekte ayrıca, kas gevşetici, ağrı kesiciler ve non-steroid antienflamatuvar ilaçlar önerilebilmektedir $(2,4,5)$. Bunların yanı sıra sıcak-soğuk uygulama, elektroterapi, lazer gibi fizik tedavi modaliteleri ve/veya masaj ve germe, eklem hareket açıklığı gibi egzersiz yöntemleri de kullanılmaktadır. Genellikle MAS tedavisinde bu tedavi yöntemlerinin birden fazla kombinasyonu kullanılmaktadır (6).

Miyofasyal ağrı sendromunda tetik nokta tedavisinde konservatif fizik tedavi modalitelerinden en çok TENS kullanılmaktadır (7). TENS'in miyofasyal ağrıdaki etkinliğini gösteren çalışmalar mevcut iken, interferansiyel akımlar gibi TENS dışı fizik tedavi modalitelerinin miyofasyal ağrıda etkinliklerini gösteren, randomize kontrollü çalışmalar kısıtlı sayıdadır.

Bu çalışmada, kronik miyofasyal ağrı sendromuna bağlı tetik nokta ağrısı olan hastalarda interferansiyel akım tedavisinin kısa dönem etkinliği değerlendirilmiştir.

\section{Gereç ve Yöntem}

\section{Hastalar ve Uygulama}

Prospektif, randomize, tek-kör, kontrollü olarak düzenlenen bu çalışma Marmara Üniversitesi Fiziksel Tıp ve Rehabilitasyon Kliniğinde, Ocak -Haziran 2007 tarihleri arasında yapıldı. Polikliniğe sırt ağrısı ile başvuran, Tablo 1'de tanımlanan MAS tanı kriterlerini (8) karşılayan, en az altı ay süre ile ağrısı olan 40 hasta çalışmaya dahil edildi. Radiküler ağrı, akut inflamasyon, tromboz, malignensi, kalp pili, hamilelik, uygulama bölgesinde duyu bozukluğu ve kronik ağrı yapabilecek tiroid fonksiyon bozukluğu gibi sistemik hastalığı olanlar çalışmaya dahil edilmedi. Hastalar kura yöntemi ile iki gruba randomize edildi. Tüm hastaların tedavi öncesi ve sonrası değerlendirmeleri kör olarak, aynı araştırmacı tarafından yapıldı. Tüm hastalardan aydınlatılmış onam ve hastanemiz etik kurulundan çalışma onayı alındı.

İlk gruba vakum + interferansiyel akım (VIFA); ikinci gruba sadece vakum tedavisi (VT) hafta içi günlerde ardışık olarak toplam 10 seans, olacak şekilde ağrılı bölgeye aşağıda tarif edildiği gibi uygulandı. VIFA grubunda interferansiyel akım $100 \mathrm{~Hz}$ frekans oluşturacak şekilde 30 dakika boyunca yapıldı. (Enraf ${ }^{\circledR}$ 182). Uygulama sırasında 2 çift sünger elektrot kullanıldı. Elektrotlar ağrı bölgesi ortada kalacak şekilde çapraz yerleştirme yöntemi ile yerleştirildi. İkinci gruba da yine ağrı bölgesi ortada kalacak şekilde vakum elektrotlar çapraz yerleştirme yöntemi ile uygulandı. Bu grupta uygulama sırasında interferansiyel akım kullanılmadı, sadece cihazın vakumları çalıştıııldı. Aynı zamanda her iki gruba ev programı şeklinde üst ekstremite ve boyun için eklem hareket açıklığı ve germe egzersizleri gösterildi ve hastalara düzenli olarak, her gün egzersizleri, günde bir kez, 10 'ar tekrarlı yapmaları gerektiği söylendi ve egzersiz yapıp yapmadıkları sorgulama ile her gün kontrol edilerek not edildi.

Hastaların Değerlendirilmesi

Hastaların ağrı şiddetleri ve ağrı eşik düzeyleri vizüel analog skala (VAS) ve algometre ile ölçülerek yapıldı. Algometrik ölçüm hastanın ifade ettiği ve palpasyonla tespit edilen gergin bant üzerindeki en ağrılı nokta üzerinden olacak şekilde üç kez yapıldı. $\mathrm{Bu}$ üç uygulamaların ortalaması alınarak değerlendirmeye dahil edildi.

Hastalık şiddeti, hastanın ve hekimin global değerlendirme skalası ile yapıldı. Hastanın global değerlendirme skalası 5 dereceli (1: yok, 2: hafif, 3: orta, 4: şiddetli, 5: çok şiddetli) değerlendirmeden oluşup, hastalara hastalık şiddetlerini "yok"'tan "çok şiddetli"'ye kadar değerlendirmeleri istendi. Hekimin global değerlendirme skalası da 5 dereceli (1: çok kötü, 2: kötü, 3: orta, 4: iyi, 5: çok iyi) idi.

Hastaların duygu durum değerlendirmeleri Beck Depresyon Ölçeği (BDÖ) skalasının Türkçe versiyonu (9) ile yapıldı.

Tüm değerlendirmeler tedavi öncesi 0. ile tedavi sonrası (15. günde) olacak şekilde, aynı araştırmacı tarafından, kör olarak yapıldı.

\section{İstatistik Değerlendirme}

İstatistiksel değerlendirmeler SPSS 10.0 programı kullanılarak yapıldı. Gruplar içi tedavi öncesi ve sonrası değerlendirmeler non-parametrik Wilcoxon testi; gruplar arası karşılaştırma ise non-parametrik Mann-Whitney U testi kullanılarak yapıldı. Nitel verilerin karşılaştırılmasında ki-kare analizi kullanıldı.

\section{Bulgular}

Çalışmaya alınan hastaların yaş ortalamaları ViFA tedavi grubunda (grup I) 38,2 $\pm 13,2$ (min: 27, max: 71 yıl) yıl ve VT kontrol grubunda (grup II) 48,2 $\pm 14,4$ (min: 18, max: 57 yıl) yıl idi. Hastaların yaş, cinsiyet, dominant taraf, tetik nokta tarafı, yakınma süreleri ve eğitim durumlarını gösteren demografik verileri Tablo 2'de görülmektedir. Tüm hastalarda sırt bölgesinde sadece bir tetik nokta mevcut idi. Yaş hariç demografik veriler açısından gruplar arasında anlamlı bir fark yoktu $(p<0,05)$. VIFA tedavi grubunda yaş ortalaması VT grubuna göre daha düşüktü $(p<0,05)$. Her iki grubun başlangıç değerleri karşılaştırıldığında, VT grubunda algometre ile ölçülen ağrı eşik değerlendirmesinin daha yüksek olduğu görüldü $(p<0,05)$. Diğer değerlendirilen parametreler açısından her iki grup arasında anlamlı farklılık saptanmadı $(p>0,05)$.

Her iki grubun çalışma başlangıcı ve sonrası değerlendirmelerinde, VAS skorları ile hasta ve hekimin global değerlendirmesinde belirgin düzelme saptandı $(p<0,05)$. Bununla birlikte, tedavi sonrasında algometrik değerlendirmede 
ViFA grubunda anlamlı bir düzelme saptanırken ( $p=0,008)$; VT grubunda algometrik değerlerde anlamlı bir fark gözlenmedi $(p>0,05)$. Her iki grupta başlangıç BDÖ skorları normal sınılar içerisinde olup, tedavi sonrasında değerlerin istatistiksel olarak anlamlı oranda azaldığı saptandı $(p<0,05)$ (Tablo 3 ).

\section{Tablo 1. Miyofasyal ağrı sendromu tanı kriterleri.}

\section{Majör Kriterler}

Bölgesel ağrı yakınması

Tetik noktadan yayılan ağrı veya rahatsızık hissi

Palpe edilebilen gergin bant

Gergin bandın uzunluğu boyunca bir noktada hassas nokta

Ölçülebilir ise hareket açıklığında biraz kısıtlanma

\section{Minör Kriterler}

Basınç uygulanması ile ağrı veya rahatsızlık hissi oluşması

Kasın transfer palpasyonu ile lokal seğirme yanıtı

Kasın gerilmesi ile ağrıda hafifleme

Not: Beş majör ve en az 1 minör kriterin pozitif olması ile MAS tanısı konulur.

\section{Tablo 2. Demografik veriler.}

\begin{tabular}{|c|c|c|c|}
\hline & $\begin{array}{l}\text { Grup I (ViFA) } \\
(n=20)\end{array}$ & $\begin{array}{l}\text { Grup II (VT) } \\
(n=20)\end{array}$ & p değeri \\
\hline Yaş (ort $\pm s d)$ (yıl) & $38,2 \pm 13,2$ & $48,2 \pm 14,4$ & $<0,05$ \\
\hline $\begin{array}{l}\text { Cinsiyet } \\
\text { Kadın (n,\%) } \\
\text { Erkek }(n, \%)\end{array}$ & $\begin{array}{l}19(95) \\
1(5)\end{array}$ & $\begin{array}{l}18(90) \\
2(10)\end{array}$ & $>0,05$ \\
\hline $\begin{array}{l}\text { Yakınma süresi } \\
6-12 \text { ay } \\
1-3 \text { yıl } \\
3 \text { yıldan fazla }\end{array}$ & $\begin{array}{l}3(15) \\
7(35) \\
10(50)\end{array}$ & $\begin{array}{l}4(20) \\
4(20) \\
12(60)\end{array}$ & $>0,05$ \\
\hline $\begin{array}{l}\text { MAS taraf }(n, \%) \\
\text { Sağ } \\
\text { Sol }\end{array}$ & $\begin{array}{l}12(60) \\
8(40)\end{array}$ & $\begin{array}{l}10(50) \\
10(50)\end{array}$ & $>0,05$ \\
\hline $\begin{array}{l}\text { Dominant taraf }(n, \%) \\
\text { Sağ } \\
\text { Sol }\end{array}$ & $\begin{array}{l}19(95) \\
1(5)\end{array}$ & $\begin{array}{l}18(90) \\
2(10)\end{array}$ & $>0,05$ \\
\hline $\begin{array}{l}\text { Eğitim durumu (n,\%) } \\
\text { Eğitimsiz } \\
\text { Ilköğretim } \\
\text { Lise } \\
\text { Üniversite }\end{array}$ & $\begin{array}{l}0(0) \\
4(20) \\
7(35) \\
9(45)\end{array}$ & $\begin{array}{l}0(0) \\
7(35) \\
6(30) \\
7(35)\end{array}$ & $>0,05$ \\
\hline
\end{tabular}

Hasta ve hekimin global değerlendirmesine göre gruplar arasında başlangıç değerlendirmeleri açısından fark görülmedi $(p>0,05)$. Her iki grubun tedavi öncesi ve sonrası arasındaki değerlendirmeleri karşılaştırıldığında ise hem hasta hem de hekimin global değerlendirmesinde istatistiksel olarak anlamlı düzelme gözlendi $(p<0,05)$. Ancak tedavi sonrası yapılan değerlendirmede gruplar arasında istatistiksel olarak anlamlı bir fark gözlenmedi $(p>0,05)$. Hasta ve hekimin global değerlendirme sonuçları Tablo 4'te görülmektedir.

Hastaların tümü çalışmayı tamamladı. Uygulama sırasında veya sonrasında VIFA veya VT kullanımına bağlı herhangi bir olumsuz yan etki gözlenmedi. Aynı zamanda tüm hastaların ev egzersiz programlarını aksatmadan tedavi boyunca yaptıkları günlük sorgulama ile öğrenildi.

\section{Tartışma}

Kas-iskelet sistemi ağrıları majör morbidite sebeplerinden biridir (10). MAS ise kas-iskelet sistemi ağrılarının majör sebeplerinden biridir. MAS, vücudun herhangi bir kasındaki tetik noktadan kaynaklanan bir ağrı sendromudur. Bu kaslarda gerginliğin artması ve fleksibilitede azalma ile spazm mevcuttur. Palpasyonla ve basınç uygulama ile de bölgesel yayılan bir ağrı meydana gelir. MAS sırt ve boyun ağrısının en sık karşılaşılan sebebidir (11). MAS oldukça yaygın bir yakınmadır. Genel poliklinik başvurularında yakınmaların \%30'unu vücudun herhangi bir bölgesinde tetik noktaya bağlı MAS oluşturmaktadır. Tedavisi kısa dönemde ağrının azaltılması ve bu etkinin sürdürülmesi için uygulanan metodları içerir. Genellikle birden fazla tedavi metodunun kombinasyonu kullanılır. Fizik tedavi modaliteleri genellikle kısa dönemde ağrının azalmasına ve kas spazmının çözülmesine yardımcı olur. Hiçbir zaman tek başına bir tedavi metodu olarak düşünülmemelidir. Fizik tedavi modalitelerinin yanı sıra ilaç tedavisi (analjezikler, kas gevşeticiler, antidepresanlar, antikonvülsanlar gibi) ve enjeksiyon yöntemleri tedaviye eklenebilir. Uygulanan tedavilerin etkinliğinin sürdürülmesi, kas gerginliklerinin azalması, kasın fleksibilitesini yeniden kazanabilmesi için egzersizler her tedavi modalitesine eklenmesi gereken yöntemlerdir. Genellikle eklem hareket açıklığı egzersizleri ile başlanır. Akut ve erken durumlarda germe egzersizleri daha fazla ağrı uyandırabileceğinden tolere edemeyen kişilerde daha geç bir dönemde başlanması önerilebilir. Güçlendirme egzersizleri en son verilmesi gereken egzersizler olup, özellikle izometrik güçlendirme tavsiye edilir (12).

ViFA: Vakum+Interferansiyel akım, VT: Vakum tedavisi

Tablo 3. Grupların tedavi öncesi ve sonrası ağrı ve depresyon değerlendirmeleri.

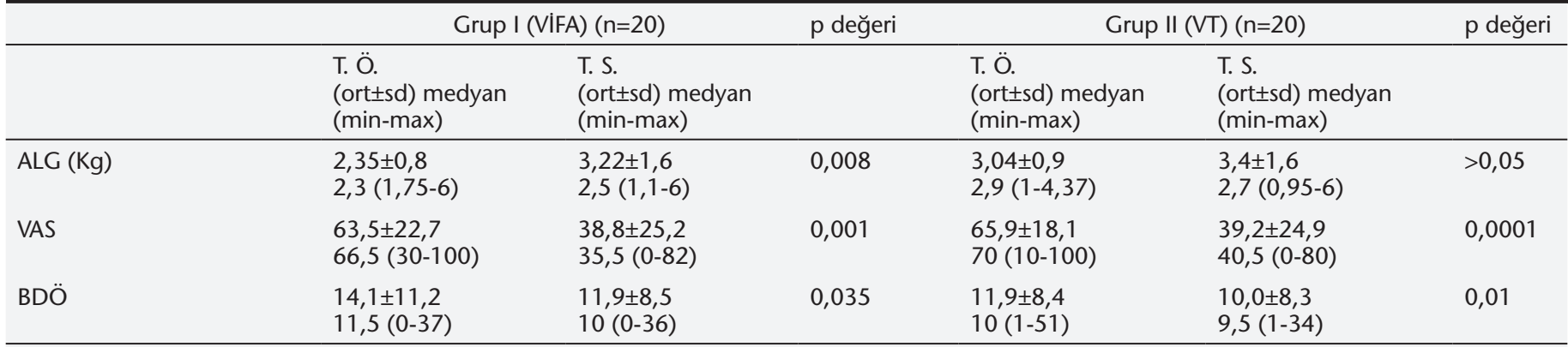

T.Ö.: Tedavi Öncesi, T.S.: Tedavi Sonrası, ALG: Algometrik değerlendirme, VAS: Vizüel Analog Skala, BDÖ: Beck Depresyon Ölçeği, ViFA: Vakum+İnterferansiyel akım, VT: Vakum tedavisi. 


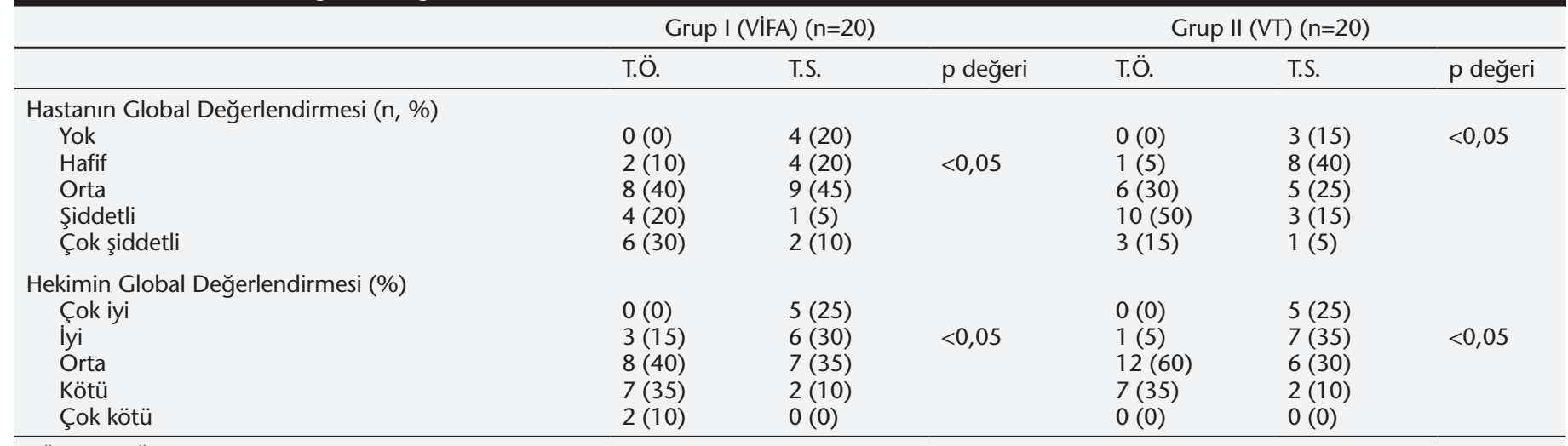

T.Ö.: Tedavi Öncesi, T.S.: Tedavi Sonrası. Her iki grubun tedavi öncesi ve sonrası değerlendirmeleri hem hasta hem de hekimin global değerlendirmesinde istatistiksel olarak anlamlı oranda farklı idi.

İnterferansiyel akımlar (IFA) çeşitli ağrılı durumlarda sık olarak kullanılan bir elektroterapi yöntemidir. Orta frekanslı akımlar grubunda olduğundan cilt direncini kolaylıkla yenebilmesi nedeniyle derin dokulara daha kolay penetre olması alçak frekanslı akımlara üstünlüğüdür (13). Yine alçak frekanslı akımların hastada oluşturduğu ağrı hissi IFA'larda oluşmadığından hasta uyumu daha iyidir. Orta frekanslı akımların tüm bu olumlu özelliklerine karşın analjezik etkileri alçak frekanslı akımlar kadar güçlü değildir. Bu nedenle iki orta frekanslı akımdan biri $4000 \mathrm{~Hz}$ diğeri $4100 \mathrm{~Hz}$ olacak şekilde hastaya uygulanır (14). Bu akımlar derin dokular içerisinde girişime uğrayarak alçak frekanslı akım oluştururlar ve analjezik etkilerini bu yeni oluşan akım üzerinden gösterirler. IFA'lar ağrıyı azaltmanın yanısıra istemli kasları etkili bir şekilde uyarabilir, periferik kan sirkülasyonunu uyararak doku oksijenizasyonunu arttırabilir, böylece toksinleri dokudan uzaklaştırabilir, kemik iyileşmesini hızlandırabilirler (13).

Pratikte oldukça yaygın olarak kullanımına rağmen, IFA'Iarın miyofasyal ağrıda etkinliği ile ilgili yapılmış yeterli sayıda randomize kontrollü çalışma yoktur. Değiş̧ik ağrı türlerinde IFA'ların pozitif etkilerini gösteren destekleyici veriler bulunmaktadır (15-17). Aynı zamanda IFA'ların ek kazanımlar sağlamadığı konusunda da çalışmalar mevcuttur $(18,19)$.

Bu çalışmada, kronik MAS olan kişilerde IFA tedavisinin vakum ve eklem hareket açıklığı ile germe egzersizlerine ek yararlarını araştırdık. VIFA grubunda algometre ile ağrı eşik değerlendirmesi tedavi sonunda tedavi öncesine göre anlamlı olarak düzelme gösterdi. VT grubunda ise algometrik değerlendirmelerde çalışma sonunda tedavi öncesine göre değişiklik göstermedi. Bununla birlikte ViFA grubunda başlangıç olarak ağıı eşik değerinin VT grubuna göre düşük olması ve tedavi sonunda istatistiksel olarak anlamlı düzelme göstermesi IFA tedavisinin vakum ve egzersize göre üstünlüğünün bir göstergesi olarak kabul edilebilir. Bunun yanısıra beklediğimiz gibi sadece vakum ve egzersiz alan grupta da, ViFA grubunda olduğu gibi, tedavi sonunda VAS değerlerinde anlamlı düzelme gözlendi. Hasta ve hekimin global değerlendirmesine bakıldığında da her iki grubun tedavi öncesi ve sonrası değerlerinde istatistiksel olarak anlamlı iyileşme tespit edildi.

Fuentes ve ark.'nın (20) IFA'ların kas-iskelet sistemi ağrıları üzerine etkinliğini araştırdığı bir meta-analizde, toplam 2235 çalışma değerlendirilmiş ancak, bunların toplam 14'ü metaanalize dahil edilmiştir. Bu 14 çalışma içerisinde tedavide sadece IFA'ların tek başına kullanıldığı çalışmaların sayısı altıdır. Bu çalışmalardan da ikisi kas-iskelet ağrısı etkinliğini değerlendiren çalışmalardı. Bu çalışmalarda da, algometrik değerlendirme dışında, bizim çalışmamıza benzer olarak IFA'nın, plasebo uygulamaya göre kas-iskelet ağrısında daha etkin olmadığı görülmüştür. Çalışmamızda, algometre ile ağrı eşik değerlendirmesi dışında, tedavi öncesine göre tedavi sonrasında her iki grupta klinik ağrı değerlendirme skorlarında belirgin düzelme olduğu görülmüştür. Bu durumun eklem hareket açıkığı ve germe egzersizlerinin yapılmış olması ve aynı zamanda vakumun kısmi masaj etkisinden kaynaklandığı düşünülmüştür. Bunun yanı sıra objektif bir değerlendirme olan algometrik ölçümler sadece IFA alan grupta düzelmiştir. Buradan yola çıkarak IFA uygulamalarının kronik MAS tedavisinde etkin olduğu düşünülmüştür. Van Der Heijden ve ark.'nın (21) yaptığı bir çalışmada, omuz bölgesinde non-spesifik yumuşak doku ağrısı olan 180 hastaya IFA+ultrason (US), IFA + plasebo US, plasebo IFA + US, plasebo IFA + plasebo US uygulanmış ve bir diğer gruba da herhangi bir uygulama yapılmamıştır. Ek olarak, her gruba egzersiz tedavisi verilmiştir. Çalışmanın sonunda, bizim çalışmamıza zıt olarak, ne IFA'nın ne de US tedavisinin egzersiz kadar etkinliği kanıtlanamamışır. Diğer taraftan, deneysel olarak, daha önce ağrısı olmayan kişilerde, iskemik ağrıda interferansiyel akım tedavisi TENS ile karşılaştııılmıştır (19). Bu çalışmada, IFA'nın ağrı üzerine etkinliğinin TENS'ten farklı olmadığı ve plasebo uygulamaya göre anlamlı oranda düzelme sağladığı görülmüştür.

Bu çalışmada, interferansiyel akım tedavisinin sadece kısa dönem sonuçlarının değerlendirilmiş olması, rölatif olarak az sayıda olgu içermesi, başlangıç yaş ortalaması ve ağrı eşik değerleri arasında gruplar arasında uyumun olmaması çalışmanın kısıtlııklarını oluşturmaktadır. Diğer taraftan, literatürde MAS'da IFA'ların etkinliğini araştıran randomize, kontrollü yapılmış çalışma sayısının az olması, çalışmamızın prospektif ve randomize-kontrollü bir çalı̧̧ma olması literatüre kanıta dayalı bilgiler sağlaması açısından önemlidir.

Sonuç olarak, sırt ağrısı ile polikliniğe başvuran, kronik MAS tanısı konan hastalarda IFA uygulamalarının etkinliğini araştırdığımız bu çalışmada, vakum ve egzersize ek olarak IFA uygulanan grupta objektif bir ölçüm olan algometrik 
ağrı eşik ölçüm değerlerinde düzelme görülmüştür. Böylece, interferansiyel akımların kronik MAS tedavisinde etkin bir tedavi yöntemi olup, egzersiz gibi diğer tedavi metodları ile kombinasyonunun tedaviye ek yararlar sağlayabileceği görüşüne varılmıştır.

\section{Çıkar Çatışması}

Yazarlar herhangi bir çıkar çatışması bildirmemişlerdir.

\section{Kaynaklar}

1. Melhorn IM, Wilkinson L, Gardner P, Horst WD, Silkey B. An outcomes study of an occupational medicine intervention program for the reduction of musculoskeletal disorders and cumulative trauma disorders in the workplace. J Occup Environ Med 1999;41:833-46.

2. Han SC, Harrison P. Myofascial pain syndrome and trigger-point management. Reg Anesth 1997;22:89-101.

3. Castro MM, Daltro C. Sleep patterns and symptoms of anxiety and depression in patients with chronic pain. Arq Neuropsiquiatr 2009;67:25-8.

4. Tsai CT, Hsieh LF, Kuan TS, Kao MJ, Chou LW, Hong CZ. Remote effects of dry needling on the irritability of the myofascial trigger point in the upper trapezius muscle. Am J Phys Med Rehabil 2010;89:133-40.

5. Simons DG. Myofascial pain syndrome due to trigger points. In: Goodgold J, editor. Rehabilitation Medicine. St Louis: Mosby; 1988. p. 686-723.

6. Wright A, Sluka KA. Nonpharmacological treatment for musculoskeletal pain. Clin J Pain 2001;17:33-45.

7. Vernon $\mathrm{H}$, Schneider $\mathrm{M}$. Chiropractic management of myofascial trigger points and myofascial pain syndrome: A systematic review of the literature. J Manipulative Physiol Ther 2009;32:14-24.

8. Thompson JM. The diagnosis and treatment of muscle pain syndromes. In: Braddom RL, Buschbacher RM, Dumitru $\mathrm{D}$ Johnson EW, Matthews D, Sinaki M, editors. Physical Medicine and Rehabilitation. 2nd ed. Philadelphia: W.B. Saunders Company; 2000. p. 934-56.

9. Hisli N. Beck Depresyon Envanterinin üniversite öğrencileri için geçerliği, güvenilirliği. Psikoloji Dergisi 1989;7:3-13.
10. World Health Organization: The burden of musculoskeletal conditions at the start of the new millennium: Report of a WHO scientific group. Geneva, Switzerland: WHO, 2003.

11. Uyar M, Aydın Ö. Miyofasyal ağrı sendromu ve diğer muskuloskeletal kökenli ağrılar. In: Erdine S, editor. Ağrı. Üçüncü baskı. İstanbul: Nobel Tıp Kitabevi; 2007. p. 476-92.

12. Yap EC. Myofascial pain-An overview. Ann Acad Med Singapore 2007;36:43-8.

13. Goats GC. Interferential Current Therapy. $\mathrm{Br}$ J Sports Med 1990;24:87-92.

14. Tuncer T. Elektroterapi. Beyazova M, Gökçe-Kutsal Y, editörler. Fiziksel Tıp ve Rehabilitasyon. 2. Baskı, Ankara: Güneş Tıp Kitapevi; 2011. s. 1007-25.

15. Jorge S, Parada CA, Ferreira SH, Tambeli $\mathrm{CH}$. Interferential therapy produces antinociception during application in various models of inflammatory pain. Phys Ther 2006;86:800-8.

16. Tugay N, Akbayrak T, Demirtürk F, Karakaya IC, Kocaacar O, Tugay $\mathrm{U}$, et al. Effectiveness of transcutaneous electrical nerve stimulation and interferential current in primary dysmenorrhea. Pain Med 2007;8:295-300.

17. Cheing GL, Hui-Chan CW. Analgesic effects of transcutaneus electrical nerve stimulation and interferential currents on heat pain in healthy subjects. J Rehabil Med 2003;35:15-9.

18. Minder PM, Noble JG, Alves-Guerreiro J, Hill ID, Lowe AS, Walsh DM, et al. Interferential therapy: lack of effect upon experimentally induced delayed onset muscle soreness. Clin Physiol Funct Imaging 2002;22:339-47.

19. Johnson MI, Tabasam G. An investigation into the analgesic effects of different frequencies of the amplitude-modulated wave of interferential current therapy on cold-induced pain in normal subjects. Arch Phys Med Rehabil 2003;84:1387-94.

20. Fuentes JP, Armijo Olivo S, Magee DJ, Gross DP. Effectiveness of interferential current therapy in the management of musculoskeletal pain: A systematic review and meta-analysis. Phys Ther 2010;90:1219-38.

21. Van Der Heijden G], Leffers P, Wolters PJ, Verheijden JD, Van Mameren $H$, Houben JP, et al. No effect of bipolar interferential electrotherapy and pulsed ultrasound for soft tissue shoulder disorders: a randomized controlled trial. Ann Rheum Dis 1999;58:530-40. 